RUNNING HEAD: ANCHORETTE SEXUALIZATION

Grabe, M. E. \& Samson, L. (2011). Sexual cues emanating from the anchorette chair: Implications for perceived professionalism, fitness for beat, and memory for news. Communication Research, 38(94), 471-496. 
Sexual cues emanating from the anchorette chair:

Implications for perceived professionalism, fitness for beat, and memory for news

\begin{abstract}
The experimental study reported here employed one of the most compelling visual cues of female sexual attractiveness (low waist-to-hip ratio) to test news anchor sexualization influences on audience evaluations of her as a professional and memory for the news that she presents. Close to four hundred subjects $(N=390)$ participated in this between subjects study. The data reveal variance in professional assessments and memory outcomes across sexualized versus unsexualized embodiments of the female anchor. Moreover, male and female participants varied in their responses. Conclusions are drawn in line with evolutionary psychology expectations of men's cognitive susceptibility to visual sex cues--here to the detriment of forming memory for news content.
\end{abstract}

Key words: Evolutionary psychology, sexual attractiveness, waist-to-hip-ratio, gender, female anchor, television news, memory, information processing. 
Recent lawsuits suggest that the broadcast news industry disfavors aging women anchors. The assumption, most likely fueled by consulting firms, seems to be that women anchors loose their audience-drawing potential by their midthirties. Beyond the age factor, anecdotal evidence points to rather dramatic changes in the grooming conventions for on-air women news workers.

Specifically, the trend is to play up sexual attractiveness. Traditional industry standards for the physical appearance of female anchors and reporters were conservative, encouraging an androgynous presence. Indeed, the old way of thinking was that the trappings associated with female sexual attractiveness would distract from the news messages that reporters deliver. But in recent times female journalists are seen wearing their hair at shoulder length or longer, they are featured with bold make-up (especially lip color), and large swinging earrings, often accompanied by a showy necklace and a cleavage-revealing neckline.

These industry trends invite an investigation of how sexual attractiveness might influence news reception. Theoretically, it entices an exploration grounded in evolutionary psychology postulates about sexual attractiveness and mate selection. The goal of the experimental study reported here is then to evaluate the potency (if any) of visual sexual attractiveness cues on men and women audience members' ratings of a female anchor's professional performance and her suitability for reporting on different news beats. Perhaps most important, by employing memory measures, this study takes stock of how female sexuality might impact the journalistic goal of informing citizens.

Being a "broad" in broadcast news ${ }^{\mathrm{i}}$ 
Since the 1980s a number of sex discrimination lawsuits emerged from broadcast newsrooms across the U.S. In 1983, Christine Craft became the first anchorwoman to sue for age and sex discrimination after being demoted from her position as co-anchor at KMBC-TV in Kansas City. According to testimony from the resulting trial, Craft's male supervisor told her that she was "too old, unattractive and not differential enough to men" (Thornton, 1983, p. A1). Barbara Howar, a reporter for "Entertainment Tonight" was quoted in reference to Craft's case as saying: "With men the gray hair and frown lines and wrinkles are marks of distinction. For women they're the kiss of death" (Smith, 1983, p. A1).

In 1999, 48-year-old anchorwoman Janet Peckinpaugh was awarded 3.79 million dollars after suing a Hartford, CT, station (WFSB-TV) for demoting her (The Boston Globe, 1999). Carol Kaplan, 41 years old, filed a gender discrimination lawsuit in 2002 against WGRZ-TV (Buffalo). ${ }^{\text {ii }}$ Another 2002 suit by 49-year old Susan Hutchis against KIRO-TV in Seattle was settled out of court in 2005, with a confidentiality agreement (Sitt, 2003). Even The Weather Channel has settled a sex discrimination suit out of court—one filed by Marny Stanier Midkiff, 41, after she was fired in 2003. Her lawyer told the press that on advice of image consultants, The Weather Channel "wanted younger women on camera," and promoted a "sexier look" with "top buttons open on the blouse" (Flint, 2005, A11). ${ }^{\text {iii }}$ Most recently (July, 2009), Fox 61 political reporter Shelly Sindland, 40, filed a complaint of gender and age discrimination (and retaliation) with the Connecticut Commission on Human Rights and Opportunities (D'Ambrosio, 2009). 
These complaints and law suits find supportive context in systematic content analysis findings (Lillie, Mader, \& Ray, 2009; Nitz, Reichert, Aune, \& Velde, 2007) and a large body of qualitative work (e.g., Carter, Branston, \& Allan, 1998; Duits \& van Zoonen, 2007; Holland, 1987; Rakow \& Kranich, 1991) as well as survey research (Engstrom \& Ferri, 2001; Ferri, 1988; Ferri \& Keller, 1986) that point to age discrimination and the sexualization of female journalists in the news--perhaps to the point where the women in this profession have become an ideal of sexual attractiveness for men. In fact, an analysis of 23, 000 "matches" by two dating agencies places female television news presenters at the top of what men ("who are looking for love") see as the perfect date (Womack, 2005).

In an elaborate account of TV news anchor sexualization, Nitz et al. (2007) found that in $64 \%$ of segments female anchors were wearing suggestive clothing with another $8 \%$ "partially clad" (p. 23). Eighty-eight percent of female reporters were rated as "high" on physical attractiveness while only $12 \%$ of their male counterparts were coded as such. Even behaviorally, women anchors (25\%) outscored men (5\%) on sexual innuendo. By focusing on "facilitation factors," defined as camera techniques that enhance sexuality, the authors report that $98.5 \%$ of news stories coded as high on sexualization were reported by female anchors.

An experimental study on the impact of age and gender on newscaster credibility offers support for the news consultant driven ideal of female youth (Weibel, Wissmath, \& Groner, 2008). While young men and women were rated as 
equally credible, older (over 40) male newscasters were perceived as significantly more credible than their female counterparts. The authors conclude that lower perceived attractiveness of older women might drive this finding.

The commotion over gender and age discrimination in newsrooms is certainly a worthy topic for public debate and academic inquiry. Yet, the study reported here is disinterested in the normative dimensions of the controversy. Understanding the human condition that underlies the alleged discriminatory practice stands at the center of this investigation.

Sexual attractiveness of the Homo sapience female

Evolutionary psychology provides scaffolding for this investigation of the television news practice to sexualize female anchors. Scholars in this tradition have demonstrated that men are more reliant on visual cues of sexual attractiveness in mate selection than women (Buss \& Barnes, 1986; Buss, 1989; Feingold, 1990; Jackson, 1992). Despite some variance across time and cultures, female attractiveness is a remarkably predictable, yet multi-dimensional, construct. Based on the stability of what heterosexual men cross-generationally and cross-culturally regard as sexually attractive, evolutionary psychologists have built arguments (1) for inherent preferences and (2) that these preferences serve reproductive fortitude.

Collectively, studies on attractiveness have dissected the female body and scrutinized variations within constituent parts for sexual attractiveness. What emerged as the male preferred variants have been linked with hormonal and health related conditions conducive to optimal female fertility and fitness for 
survival. A few examples include face symmetry, lip fullness, smooth skin, low waist-to-hip-ratios (hourglass body shape), and long lustrous hair (Buss, 1989; Fink \& Penton-Voak, 2002; Johnston, 1999; Singh, 1993; 2004; Singh \& Randall, 2007). Beyond the obvious visual cue of youthfulness, these physical attributes have been positively linked to a host of health and fecundity variables in women (Grammer, Fink, Moller, \& Thornhill, 2003; Symons, 1979; Singh, 1993, 2006; van Hoof, 2000). The male predisposition to be drawn to these physical attributes is therefore seen as inherent and reproductively functional. Put simply, “...males failing to prefer females possessing attributes that signal high reproductive capacity would, on average, leave fewer offspring than would males who do prefer to mate with females displaying these attributes" (Buss, 1989, p. 2). In this sense the longevity of male genes are dependent on female fertility, the ability to carry a fetus to term, birthing without complications, and the good health of a mother who will survive long enough to nurture offspring to independence. Physical attributes of the Homo sapience female offer a visually apparent shortcut for males to these reproductive and health potentials.

In the large body of evolutionary psychology literature on female sexual attractiveness, waist-to-hip ratio stands out as one of the most potent predictors of female sexual attractiveness (Dural, Çetinkaya, \& Gülbetekin, 2008; Gründl, Eisenmann-Klein, Prantl, 2009). In fact, a low waist-to-hip ratio has been linked, across 20 cultures worldwide, as a significant predictor of female sexual attractiveness and a persistent feature in artifacts--even in ancient Greek, Egyptian and Indian times--that celebrate the female form (Singh, 2006). 
Women show some awareness of the male propensity to experience sexual attraction in response to visual cues (Jackson, Sullivan, \& Rostker, 1988). The history of self-adornment through clothing and grooming speaks to the female pre-occupation with enhancing sexual attractiveness. Facial "imperfection" (asymmetry and skin unevenness) is "corrected" through make-up, lip fullness enhanced with lipstick, and waist-to-hip ratio's flaunted as a basic fashion standard. Dating back to ancient Egypt around 10,000 BCE, red lipstick has a particularly long social history in service of women's attempts to boost their sexual attractiveness (Regas \& Kozlowski, 1998). Interestingly, Elliot and Niesta (2008) established, across 5 experiments, that adding the color red to photographs of female targets, significantly enhanced men's sexual attractiveness ratings of them, how interested they are in dating the women, and how much money they would spend on dating them. The authors point to the time-honored social and biological contexts for the "red-sex link" (Elliot \& Niesta, 2008, p. 1151). In fact, red ochre was used to decorate women's faces and bodies in ancient rituals to announce female fertility. Biologically, there is ample evidence to link red skin color to female sexuality, including facial and labial vascularization during ovulation and sexual excitation (Elliot \& Niesta, 2008).

In studies of men and women's strategies to appear sexually attractive to a partner, appearance alterations that include grooming (make-up and jewelry) and dress (revealing and stylish) have emerged as prominent female maneuvers (Buss, 1988; Cashdan, 1996; Kardum, Hudek-Knezevic, \& Gracanin, 2006). Women might also unknowingly enhance their sexual attractiveness through 
ornamentation, as Haselton, Mortezaie, Pillsworth, Bleske-Rechek, and Frederick (2007) demonstrated in a study that tracked women's clothing and grooming choices throughout their menstrual cycle. They found that during ovulation women tend to wear more revealing clothes and accessories and these photographs were rated as higher on "trying to be attractive" than photographs taken during non-fertile phases of the cycle (p. 42).

While acknowledging normal variation, evolutionary psychologists have argued and offered evidence that female sexual attractiveness is indeed not in the eye of the beholder. Instead, they argue, it is a stable and predictable construct with reproductively functional outcomes for men. This large body of research, however, offers little insight into how sexual attractiveness in the contemporary Homo sapiens female affects her professional life. On this point, research on female attractiveness and the workplace has to be consulted.

Female sexualization and professional life

Two bodies of literature, one on morphological facial attractiveness and the other on clothing and grooming enhanced attractiveness, offer insight into the influences of sexual cues on a women's perceived professionalism. First, studies of facial attractiveness show that attractive people are seen as socially more competent than unattractive people (Dion, Berscheid, \& Walster, 1972; Eagly, Ashmore, Makhijani, \& Longo, 1991). This is known as the "what is beautiful is good" hypothesis (Dion, et al., 1972) which was picked up in studies of perceived professional competence. Meta-analyses show that attractive people (regardless of their gender or the gender of the subjects evaluating them) are seen as 
professionally more competent than unattractive people (Hosoda, Stone-Romero, \& Coats, 2003; Langlois, Kalakanis, Rubenstein, Larson, Hallmam, \& Smoot, 2000). The "what is beautiful is good" hypothesis has also spawned a series of investigations that produced evidence to suggest that beauty in the workplace is (1) overall more beneficial to men than women (see meta-analysis by Heilman \& Stopeck, 1985) and (2) beneficial to women only in the context of jobs stereotypically associated with women (e.g., non-managerial--see Cash, Gilen, \& Burns, 1977; Heilman \& Saruwatari, 1979). Across these studies a number of dependent variables were used, ranging from evaluations of job competence and hire-ability to salary recommendations and explanations for success in the workplace.

Although relevant to the study reported here, most of the work on the role of facial attractiveness in the workplace used still photographs depicting different targets who vary in levels of facial attractiveness. In the study reported here, a full motion depiction of a woman anchor performing professional work will be used. Moreover, subtle grooming manipulations were performed on the same female anchor, which has been shown to result in less variance in attractiveness ratings between subjects than choosing several different people who vary in facial attractiveness (Eagly, et al., 1991).

A second area of research, focused on grooming for workplace success matches perhaps more closely the experimental manipulation pursued in the study reported here. During the 1980s and early 1990s a few such experimental studies 
were conducted. Although there are some inconsistencies, evidence lines up with the research on facial attractiveness.

Forsythe, Drake, and Cox (1985) report that a masculine style ${ }^{\text {iv }}$ of dress were favored in hiring decisions for women. Cash (1985) reports a high level of agreement between experimental raters on what constitutes a managerial versus non-managerial appearance. Striking make-up and jewelry as well as tight fitting clothes and low necklines are associated with a non-managerial appearance similar to the sexualized appearance manipulated in the study reported here. Managerial appearance involve little make-up, simple jewelry, and high necklines, resembling the unsexualized condition pursued in our study. The women appearing in the Cash (1985) managerial condition were rated as more appropriate for management training, more likely to be hired as a manager, and received higher salary recommendations - especially from male subjects. Women subjects, for some dependent variables, favored the non-managerial appearance. Using the Cash (1985) managerial appearance as the well-groomed condition in comparison to a poorly groomed ${ }^{\mathrm{v}}$ version of the same female target, Mack and Rainey (1990) conducted two experimental studies. They report that the wellgroomed managerial appearance increased perceptions of the female target's hiring potential for managerial jobs--that, despite subject denials that physical appearance influenced their ratings.

Cox and Glick (1986) demonstrated that make-up use enhances perceptions of a woman job applicant's femininity, attractiveness, and sexiness. But it had strong negative implications for expectations of work performance- 
specific to jobs stereotypically associated with women (i.e., secretarial). At the same time, make-up use did not have negative consequences for women who were applying for a more gender-neutral job (i.e., accountant). Both men and women subjects were included in this experiment and no gender variance was reported.

In the only known experimental study that manipulated the clothing of television news anchors, Harp, Harp, \& Stretch (1985) found that conservative dress for men and women anchors produced the highest credibility scores among adult viewers. The other two dress conditions were trendy and casual. Of the three clothing versions, the casual dress manipulation comes closest to resembling a sexual cue. The authors report that the female anchor's top was "slightly open at the neckline with a stand-up collar piped in red cording” (p. 52). Yet, anchors were seen behind a anchor desk, not revealing the waist-to-hip ratio of the female anchor.

Despite the somewhat incomparable manipulations and measures, experimental research on the professional benefits of female sexual attractiveness (facial and grooming/clothing-induced) challenges the sweeping scope of the "what is beautiful is good" hypothesis. In fact, it appears that high levels of attractiveness might have detrimental influences on a woman's perceived professional cachet. The first hypothesis prompts a test for this supposition:

H1: There will be a main effect for grooming such that the unsexualized version of the anchor will be rated higher on professionalism than the sexualized version of the anchor. 
Luxen and van der Vijver (2006) found consistently, across three different experiments, that women are less likely to hire facially attractive women than men and are also less likely than men to hire facially attractive women. Most grooming, clothing, or facial attractiveness studies report no gender differences across raters for evaluations of professional competence (see Heilman \& Stopeck, 1985; Heilman \& Saruwatari, 1979). Moreover, in hip-to-waist ratio studies gender differences between men and women raters are often not found (Gründl, Eisenmann-Klein, Prantl, 2009) or reported. Even in experimental studies on the credibility of anchors (Weibel, et al., 2008) and spokespeople in print advertisements (Patzer, 1983) gender differences between raters were reported as non-existent. The scarcity of evidence to support gender differences between raters prevents hypothesis testing. Nonetheless this is an important factor to consider in the context of this study, and therefore prompts two research questions:

RQ1: Is there a main effect for the rater's gender on evaluations of the anchor's professionalism?

RQ2: Is there an interaction effect between grooming and the rater's gender on evaluations of the anchor's professionalism?

Gender and fitness for beat

While the number of women in newsrooms is surging, few women make it to the upper echelon of management (Creedon \& Cramer, 2007; Steiner, 2007; Weaver et al., 2007). Women reporters, although plentiful in number, are also strangely confined to specific news beats. Specifically, they are assigned with 
greater frequency to what has been called feminine topics, soft news, or human interest stories about entertainment, health-care, and education than masculine or hard news topics (politics, war, and economics) that lead newscasts (Beasley \& Creedon, 1989; Cann \& Mohr, 2001; Desmond \& Danilewicz, forthcoming; Kim, 2006; Lumby, 1994; Nicholson, 2007; Soderlund, Surlin, \& Romanow, 1989; Thiel Stern, 2007).

This well-documented gender divide in story assignments might persist, at least in part, because women reporters are hired and fired for sexual attractiveness. This newsroom practice might perpetuate a gendered rather than professional view of female journalists. This study offers an opportunity to assess if sexual cues prime audience evaluations of a female reporter's fitness to report on different news topics. Smee (2004) reports a sweeping gender bias associated with story topics. Men and women subjects alike favored hiring men for hard and women for soft news. The question remains if an unsexualized female anchor would be seen as better suited for hard news topics than the sexualized embodiment of her. This leads to the following three research questions: RQ3: Is there a main effect for grooming such that the sexualized version of the anchor will be rated as a better fit for feminine beat (entertainment and education) reporting and less suited for masculine beat (war and politics) reporting than the unsexualized version of the anchor? RQ4: Is there a main effect for rater gender on evaluations of the anchor's fitness for feminine and masculine beat reporting? 
RQ5: Is there an interaction effect between grooming and the rater gender on evaluations of the anchor's fitness for feminine and masculine beat reporting?

\section{Sexualization and memory}

This study relies on the limited capacity model to investigate the effects of visual sexual cues on visual and verbal memory. The limited capacity model of motivated mediated message processing (LC4MP; Lang, 2006a; 2009) treats media consumers as information processors with controlled and automatic mechanisms for allocating resources to message processing. Message features influence how the cognitive system dispenses these limited reserves for memory formation processes. For example, visually compelling messages have been found to automatically engage attention and they receive priority for encoding, storage and retrieval processes (Lang, Newhagen \& Reeves, 1996; Lang, Potter, Bolls, 1999; Newhagen \& Reeves, 1992). Research on visual primacy in information processing has strong roots in evolutionary theory (see Grabe \& Bucy, 2009). The most sophisticated of our senses to evolve, the eyes "send more data more quickly and efficiently through the nervous system than any other sense" (Barry, 2005, p. 48). Indeed, media researchers have shown that visual processing is a highly efficient, relatively resource-free, and automatic process (Basil, 1992; Graber, 1990; Grimes, 1991; Lang, Potter, Bolls, 1999).

In line with the visual primacy tenor, LC4MP proposes that mediated stimuli activate appetitive and aversive motivational systems of viewers (LC4MP; Lang, 2006a; 2009). Appetitive appeals in messages, such as the sexual cues 
manipulated in the study reported here, activate the approach system, elicit positive arousal, draw resources, and subsequent memory formation. This line of theoretical thinking leads to the second hypothesis:

$\mathrm{H} 2$ : There will be a main effect for visual memory on anchor grooming such that the sexualized version will be encoded better than the unsexualized version.

While visual sexual cues are likely to draw cognitive resource allocation to visual processing, it might happen at the expense of resource distribution to encoding the verbal content that the anchor delivers. Indeed, appetitive stimuli, especially in visual form, will place a heavy burden on available information processing resources. Moreover, visual sexual cues might be regarded as incongruent with the anchor's verbal account of non-sexual news information. In media research this discord is known as lack of audio-visual redundancy. A number of studies have demonstrated that incongruency between audio and video channels produce cognitive overload. Subsequently, memory for semantic content decreases, while memory for visual information is practically unaffected (Drew \& Grimes, 1987; Grimes, 1991; Lang, 1995; Lang, Potter, Bolls, 1999; Thorson \& Lang, 1992).

Literature on grooming offer little guidance for predictions of memory. Harp, Harp and Stretch (1985) found no difference in cued recall of news content across three grooming conditions of a female anchor. Moreover, the few studies that tested memory related to attractiveness manipulations of sources report no main effects associated with male (Snyder \& Rothbart, 1971, Horai Naccari, \& 
Fatoullah, 1974) or female (Blass Alperstein, \& Block, 1974) sources. Despite the lack of evidence for memory effects associated with grooming manipulations, this study proposes the third hypothesis, grounded in LC4MP and the audio-visual redundancy literature:

H3: There will be a main effect for verbal memory on anchor grooming such that the news information presented by the unsexualized version will be encoded better than the information presented by the sexualized version.

The question remains if men and women will vary in their appetitive responses to the anchor's sexual cues. Men have been shown to treat visual appearance markers more centrally in what they consider as sexually attractive (Buss \& Barnes, 1986; Buss, 1989; Feingold, 1990; Jackson, 1992). With few exceptions (e.g., Grabe \& Kamhawi, 2006), LC4MP studies have generally shied away from testing variance associated with gender, in message processing.

A study of the persuasive power of decorative (sexy female) models on male subjects in advertising messages found no main effect on brand name recognition but report a main effect on advertisement recognition (Chestnut, LaChance, \& Lubitz, 1971). In a comparable study, Steadman (1969) used advertisements with and without female models in different stages of undress. Seven days after exposure, male subject brand name recall was better for the ads without partially undressed models. Without pertinent evidence to guide predictions for this study, the following two (final) research questions were formulated: 
RQ 6: Are there main effects for rater gender on visual and verbal

message encoding?

RQ: 7: Are there interaction effects between anchor grooming and rater gender on visual and verbal encoding measures?

\section{Method}

This experiment employed a $2 \times 2$ between subjects factorial design: Gender of Respondents (male versus female) and Anchor Grooming (sexualized versus unsexualized) were the main factors. A 24-year-old female local news anchor with shoulder-length brown hair and normal weight was recruited as the talent for the experimental stimuli. Manipulation of three visual sexual cues (waist-to-hip ratio, red lipstick, and neck jewelry) enabled a high level of experimental control. The anchor, the news content she delivered, her hair, eye make-up, and every other aspect of her appearance were held constant.

She was positioned standing in the same spot in a local news (PBS) studio and read five news stories from the teleprompter to simulate a short newsbreak. The anchorwoman was framed in a medium-long shot to reveal her upper body, including her upper thighs, waist, and hips. The news stories were about local matters, including United Way fundraising, interest rate changes for Federal Loan programs, efforts to control plant diseases in a local nature preserve, birdwatching opportunities at a lake, and a women's history event. Dependent variables:

Open-ended responses. The first portion (section A) of the questionnaire asked respondents to write down five descriptive phrases to summarize their 
impressions of the reporter. Followed by this, they were asked to write down the one best thing they observed about her (Section B) and then the one worst observation about her (Section C). The strategy here was to first provoke thought listing without valence cues and then to prime valenced (positive and negative) responses. These three sections were subjected to a content analysis with a high level of reliability between two coders in a pre-test (Krippendorff's Alpha $=.89$; $N=60)$ and in a post-test (Krippendorff's Alpha $=.96 ; N=70$ ). For section A open-ended comments were coded as either professional, personal, or physical appearance attributes. Each comment was also coded in terms of valence (positive, neutral or negative). For sections B and C coders assessed if the comments were indeed positive or negative and then coded the remarks as either professional, personal, or physical appearance attributes.

Forced choice responses. To assess evaluations of the anchor's professional performance, five nine-point semantic differential items were used. These questions asked about the anchor's believability, trustworthiness, informativeness, her level of professionalism, how articulate she was, and the importance of the information she presented. A professionalism index built with these variables was highly reliable: Cronbach's Alpha $=.82$.

A second group of items asked participants to rate the reporter's fitness to report on war and politics (masculine) as well as entertainment and education (feminine) stories. The questions were worded as: "How good will this news reporter be as a correspondent on $\mathrm{X}$ issues?"

To control for prior exposure to the news anchor, a question asking if 
subjects are familiar with her was included. Demographic data (age and gender) and television news viewing habits (how often in an average week) were collected. These three items served as a short distracter task before the memory tests.

Verbal message encoding was assessed using 10 multiple choice questions (two per story), each with five options, about the informational content of the news stories. Visual encoding of the anchor's appearance was tested through four multiple choice items, each with five options. These questions tested encoded visual memory for the anchor's physical appearance (e.g. hair color and length, jewelry, and clothing).

\section{$\underline{\text { Participants: }}$}

Three hundred-and ninety subjects were randomly assigned to one of the two conditions. Subjects participated in small groups of about 20 and watched the stimuli on a large screen in a room. After exposure to the stimuli, they were asked to complete the open-ended questions on the questionnaire, followed by the scaled items, their demographic information and news viewing habits, and finally the verbal and visual memory tests were completed.

Only one subject was familiar with the anchor and was excluded from data analysis. An analysis of subject age revealed that three subjects were older than 30. They were also excluded from data analysis to narrow age variance. The mean age of the remaining subjects was 20.08, minimum $=18$ and maximum $=29$. With four participants excluded form the analysis $(n=386)$, the cell breakdown for the two independent variables was as follows: Males, unsexualized version = 
89; males, sexualized version $=104$; females, unsexualized version $=89$; females, sexualized version $=104$.

Manipulation check:

A manipulation check confirmed that the anchor's sexual attractiveness varied across the two conditions, in the way it was intended. Eighty-two subjects viewed both versions of the anchor, side-by-side and without sound in the same experimental room where the data for this study were collected. Muted sound directed attention to visual evaluation and enabled a side-by-side comparison of the anchor's visual appearance. As Eagly et al. (1991) pointed out, comparative within subjects evaluations of the same target offers a direct way to assess sexual attractiveness. Because this study is interested in measuring memory, this within subjects design, effective for the manipulation check, was not conducive to the experimental data collection.

A questionnaire asking manipulation check subjects to answer the same six questions for both anchor versions included items about her femininity, attractiveness, dating potential, and sexiness (Regas \& Kozlowski, 1998). Ninepoint semantic differential items were used. The paired samples $t$-test results for the manipulation check questions are summarized in Table 1 and shows consistent significant differences between the two anchor versions. The sexualized version of the anchor was indeed rated as more feminine and sexually desirable than the unsexualized version.

\section{--Insert Table 1 here--}

\section{Data Analysis:}


Between subjects 2 (gender of participants) by 2 (grooming) ANOVA tests were performed. To control for possible variance introduced by the age of subjects and their television news viewing habits two variables, accounting for these dimensions, we included as covariates in all ANOVA tests.

\section{Findings}

Professional performance of the anchorette

Several ANOVA tests were performed using the (1) professionalism index (constructed from scaled items) and (2) open-ended comments prompted without a valence cue (section A of the questionnaire) and prompted by cues for positive and negative comments (sections B and C). In section A, 434 professional comments were made about the anchor. Three hundred were positive, 94 were negative, and 40 were neutral. More than half the subjects $(N=263 ; 68.13 \%)$ made professional comments about the anchor, at a average of 1.56 per subject. When subjects were prompted to make a positive comment about the anchor, 155 (43.79\%) did so, resulting in 176 remarks with a mean of 1.14 per subject. In response to the negative cue $109(29.38 \%)$ subjects referred negatively to the anchor's professionalism. A total of 129 negative comments were made, at an average of 1.18 per subject. Significant results are reported in Table 2.

--Insert Table 2 here--

\section{Main effects for version}

Hypothesis 1 predicted that the unsexualized anchor version will be perceived as more professional than the sexualized one but there was no main effect for version $(F<1)$ on the professionalism index. Open ended comments 
were examined next. For section A (no valence prompt) an ANOVA test on subjects who made professional comments $(N=263)$ revealed that the unsexualized version $(M=1.78, S E=.08)$ prompted significantly more professional comments than the sexualized $(M=1.54, S E=.07)$ version. Analyses of the valence in these comments followed. There were no main effects for positive or negative comments $\left(F^{\prime} s^{<1}\right)$ but there was a main effect for neutral comments. The unsexualized version provoked significantly (see Table 2$)$ more neutral $(M=.22$, $S E=.04)$ comments than the sexualized version $(M=.09, S E=.03)$. Taken together, these analyses of open-ended comments offer little support for hypothesis one. At best, the unsexualized version prompted more and more neutral professional comments than the sexualized version.

From here the analysis turned to examinations of open-ended comments prompted for positive and negative response (sections B and C). Subjects who made positive professional comments about the anchor did so significantly more often (see Table 2$)$ in the sexualized $(M=1.20, S E=.04)$ than unsexualized $(M=1.07, S E=.04)$ condition. Yet, subjects who make negative remarks did so without version difference, $(F<1)$.

In summary, the unsexualized version of the anchor provoked more openended comments about professionalism, suggesting she is thought of in professional terms more when she is not emitting sexual cues. Yet, analysis of the prompted positive comments showed that the sexualized version earned more professional approval from subjects than the unsexualized version. Contrary to hypothesis one, the data offer weak evidence that sexual cues might enhance 
positive evaluations of a female anchor' s professional performance.

\section{Main effects for gender}

Research question one asked for an assessment of potential gender main effects on professional ratings of the anchor. The professionalism index produced a main effect for gender (see Table 2) with male participants $(M=6.34, S E=.10)$ rating the anchor higher than female participants $(M=5.98, S E=.10)$.

Content analysis data on the number of professional comments in section A (unprompted for valence) produced no main effects for gender, $F<1$. Yet, an analysis of the valence of the comments delivered two main effects. On positive comments the main effect approached significance (see Table 2). Men $(M=1.26$, $S E=.08)$ made more positive comments than women $(M=1.03, S E=.09)$ and women $(M=.47, S E=.05)$ made significantly more negative professional comments than men $(M=.25, S E=.05)$. There was no main effect on the neutral comment scores, $F<1$. The next step was to examine comments that were prompted for valenced comments.

There was no main effect for gender on professional comments that followed a prompt for positive commentary, $F<1$. Yet, the main effect for professional comments followed by a prompt for negative remarks approached statistical significance (see Table 2$)$. Men $(M=1.24, S E=.05)$ emerged as more negative than women $(M=1.10, S E=.06)$.

In summary, the findings produced by the professional index and the open ended comments unprompted for valence delivered strong indications of greater female than male negativity toward the anchor's professionalism. Yet, when 
prompted to make negative remarks, men did so with greater frequency than women.

\section{Interaction effects for version by gender}

Research question two asked for assessments of interaction effects between participant gender and version. The professionalism index produced a significant interaction illustrated in Figure 1. Post-hoc $t$-tests show that men and women varied most on professional evaluations of the sexualized version, $t(205)=2.96, p=.003$, with men's $(M=6.53, S E=.14)$ scores significantly higher than women's $(M=5.88, S E=.13)$. There was no gender difference $(t<1)$ on ratings of the unsexualized version. Also noteworthy, there were no differences, $t(191)=1.03, p=.307$, between women's ratings of the two versions, while men rated the sexualized $(M=6.53, S E=.14)$ version higher on professionalism than the unsexualized $(M=6.14, S E=.15)$, at a close to significant level, $t(190)=-1.85$, $p=.066$.

--Insert Figure 1 here--

The open-ended comments delivered no interaction effects on section A data: professional comments, $F(1,263)=1.71, p=.192$; positive comments, $F<1$; negative comments, $F<1$; and neutral comments, $F(1,263)=2.22, p=.139$. There was no effect on prompted positive comments (section B) either, $F<1$. Yet, for prompted negative comments (section C), the interaction was significant and is graphically represented in Figure 2.

--Insert Figure 2 here--

When prompted to make negative comments, men $(M=1.72, S E=.04)$ were 
significantly, $t(53)=2.80, p=.007$, more likely to make remarks about the unsexualized version than women $(M=.91, S E=.04)$. While women's critical comments increased from the unsexualized to the sexualized condition, and men's decreased, there were no other significant differences between cells. In line with the professionalism index interaction effect, this interaction offers evidence that male subjects looked more favorably on the professional competence of the sexualized than unsexualized version of the anchor.

Fitness for different news beats

Three research questions prompted ANOVA analyses to determine if there were main effects for version and subject gender, and an interaction between these two factors on subject evaluations of the anchor's fitness to report on different news topics. News topics were classified as masculine (war and politics) and feminine (entertainment and education). Significant results are summarized in Table 2.

There was a significant main effect for version on both items related to the masculine beat, war and political reporting. Subjects rated the unsexualized version as more fit for reporting on war $(M=4.83, S E=.17)$ and politics $(M=5.82$, $S E=.16)$. Yet, the ratings for fitness to report on feminine topics did not produce main effects, $F$ 's $<1$.

Although one would expect the presence of sexual cues to trigger reproductive signals and intensify the awareness of the anchor's femininity, the data did not support this. The answer to research question 3 is therefore that 
sexualization weakened evaluations of competence to report on masculine topics but did not hike evaluations of her fitness to report on feminine topics.

Research question four prompted tests for gender differences on evaluations of the anchor's fitness for feminine and masculine beat reporting. There were no main effects for rater gender on fitness for beat evaluations, neither for masculine topics $\left(F^{\prime} s^{\prime}<1\right)$ or feminine topics, entertainment: $F(1,385)=1.086$, $p=.298$ and education: $F(1,385)=.904, p=.342$.

Tests for interaction effects, prompted by research question five, produced significant results for both masculine beat topics. The fitness for war reporting interaction is displayed in Figure 3 and the suitability for political reporting interaction in Figure 4.

--Insert Figures 3 and 4 here--

These figures and post-hoc $t$-tests indicate that male participants drove the significant interactions. Men's ratings of the anchor's fitness to report on war, $t(191)=4.113, p<.001$, were higher for the unsexualized version $(M=5.16, S E=.24)$ than sexualized version $(M=3.72, S E=.22)$. At the same time, there was not a significant difference $(t<1)$ for female participant ratings on the unsexualized $(M=4.51, S E=.24)$ versus sexualized version $(M=4.29, S E=.22)$. The same pattern exists for political reporting. Men rated the unsexualized version $(M=6.09$, $S E=.24)$ significantly, $t(189.92)=4.117, \mathrm{p}<.001$, more fit than the sexualized version $(M=4.77, S E=.22)$ while female participants did not vary significantly $(t<1)$ in their ratings of the unsexualized $(M=5.556, S E=.24)$ versus sexualized version $(M=5.553, S E=.22)$. 
The sexualized version also drove gender differences. In the case of war it approached significance, $t(206)=-1.836, p=.06$ with men's scores $(M=3.72$, $S E=.22)$ lower than women's $(M=4.29, S E=.22)$. In the case of political reporting, there was a significant difference, $t(206)=-2.500, p=.01$ between men $(M=4.77$, $S E=.22)$ and women's $(M=5.55, S E=.22)$ ratings.

In answering research question five, it is clear that the presence of sexual cues significantly lowered the anchor's perceived fitness for reporting on masculine topics--notably in the eyes of male respondents only.

Effectiveness to inform citizens

Hypothesis two predicted poorer visual memory and hypothesis three predicted better verbal memory associated with the unsexualized than sexualized version of the anchor. The main effect for grooming was significant for visual memory (see Table 2), but not for verbal memory, $F(1,385)=2.317, p=.129$. Thus, sexualization did not significantly influence encoding of verbal content but it affected visual encoding in the predicted direction: overall subjects remembered more about the physical characteristics of the sexualized $(M=2.73, S E=.07)$ than unsexualized $(M=2.47, S E=.07)$ version of the anchor. In short, hypothesis two is supported, hypothesis three is not.

When participants' gender is taken into account, as research question six calls for, significant main effects for visual and verbal memory surfaced. Men $(M=5.97, S E=.14)$ outperformed women $(M=5.36, S E=.14)$ on verbal memory tests, while women $(M=2.90, S E=.07)$ remembered more about the visual appearance of the anchor than men $(M=2.30, S E=.07)$. 
Research question seven prompted ANOVA analyses for interaction

effects on the two memory measures. Both were significant. The verbal memory interaction (see Table 2) is represented in Figure 5 and one for visual memory in Figure 6.

--Insert Figures 5 and 6 here--

While women's verbal encoding increased, at a close to significant level, $t(191)=-1.817, \mathrm{p}=.07$, from the unsexualized $(M=5.11, S E=.20)$ to sexualized version $(M=5.61, S E=.19)$, men's followed the opposite direction. In fact, men encoded significantly, $t(191)=3.839, \mathrm{p}<.001$, more information watching the unsexualized $(M=6.51, S E=.20)$ anchor deliver news than her sexualized $(M=5.43$, $S E=.19)$ version. It is important to note that for the sexualized version there was no gender difference, while the unsexualized version significantly, $t(176)=4.774$, $\mathrm{p}<.001$, varied across gender.

The means for visual memory offer some insight into the verbal memory findings. Overall, women's scores on the visual encoding test differed little $(t<1)$ across the unsexualized $(M=2.91, S E=.11)$ and sexualized versions $(M=2.88$, $S E=.10)$. But men's varied significantly, $t(191)=-3.633, \mathrm{p}<.001$. In fact, men displayed strikingly poor encoding of the physical characteristics of the unsexualized $(M=2.02, S E=.10)$ compared to the sexualized version $(M=2.58$, $S E=.10)$. It is also important to note that both the sexualized, $t(206)=-2.400$, $p=.01$, and unsexualized versions significantly impacted $t(176)=-5.538, p<.001$ men and women's ability to encode visual information about the anchor. 
Taken together, the encoding measures provide a clear answer to research question seven. Men paid attention to the visual appearance of the sexualized anchor to the detriment of encoding the news information she delivered. When the sexual cues were absent, men performed better on recognition memory for news facts and showed fairly poor encoding of visual information about her appearance. On the other hand, sexual cues prompted women to encode more news content while they maintained relatively high levels of visual encoding across the two grooming versions.

\section{Discussion}

The investigation of professionalism ratings produced two version by gender interaction effects that, taken together, reveal that men perceived the sexualized version of the anchor as more professional than the unsexualized version. Moreover, men are more critical than women of the unsexualized anchor's professionalism. If it is the intention of news consulting firms to promote perceptions of anchor professionalism among male viewers, it appears that emphasis on the sexual attractiveness of female anchors might be good advice.

On initial consideration, these findings for male participants appear to stand in contradiction to the literature on female physical attractiveness in the workplace. In fact, this body of research points to the professional benefit of conservative attire and argues that little is to be gained from female physical attractiveness in the workplace. But that position is indeed unchallenged by our findings on professionalism ratings. The inner workings of the workplace might very well be hostile to sexually attractive women, despite the anecdotal evidence 
of firing aging female news workers to hire younger attractive ones. What we demonstrate here is that at the reception end of female television news worker labor (news information) the attractiveness of the messenger boosts perceived professionalism — among male audience members.

Perhaps more important than garnering audience impressions of professionalism is the journalistic goal to inform the public. On this dimension, the sexualization of a female messenger is not productive, at least not for informing male viewers. In line with the old-school wisdom of television news directors, emphasis on the sexual attractiveness of female news anchors distracts from memory formation for news content. The data reported here showed that male subjects have good memory for visual appearance characteristics of the sexualized compared to the unsexualized version of the anchor, but their memory for the news content delivered by the sexualized anchor version suffered. It is quite likely that sexual attractiveness of a female anchor might initially attract viewer attention but the negative consequences for encoding news content are clear form this study's findings.

Women viewers, overall, seem to pay close attention to the physical appearance of a woman anchor, as evidenced by their high overall visual memory for the anchor's physical appearance across versions. At the same time, higher levels of sexualization made them encode more verbal information. It might be too early to propose that a female competition hypothesis is at work here. But it is striking that the sexualized version closed the gender gap on the amount of encoded news information. While women maintained high levels of visual 
memory across conditions, their cognitive systems managed to assign extra resources to verbal encoding when sexual cues were present. In this sense, sexualization of female reporters might be productive in the pursuit of informing female citizens.

These findings offer evidence of the evolutionary psychology tenure that men are highly affected by visually delivered sex cues. It also adds to the mounting evidence of visual primacy in information processing. Human beings, and in this case men specifically, privilege visual processing when it competes with the verbal mode of communication. Indeed, when confronted with sexual attractiveness cues in the visual modality and non-sexual news information in the verbal modality, men's cognitive mechanisms favored visual over verbal information processing. Women on the other hand were not distracted by the modal incongruency. In fact, their cognitive system managed to allocate resources, beyond what was spent on visual processing, to encode verbal news content. It appears that visual primacy might, in the face of a sexually appetitive cue, manifest in the Homo sapiens male to levels that demand close to full cognitive capacity. For females it can be seen, in the context of this study's findings, as cognitive kindle that rallies resource allocation to processing verbal information. These gender differences in information processing deserve further research attention.

This study also offers evidence--perhaps discouraging to those who have been engaged in normative debate about women's status in journalism--that gender stereotypes exist. In particular, sexual cues harden men's perceptions of a 
woman's ineptness to report on traditionally masculine story topics such as war and politics. Women seem to be immune to this effect. They saw no difference between the sexualized and unsexualized anchor's fitness and ability to report on war and politics. Given that men dominate executive decision-making positions in newsrooms, including story assignments, this discrepancy between how men and women see a sexually attractive women's professional competence, might fuel gender tension in the workplace. In this vein then, Heilman and Saruwatari's (1979) advice that "women should strive to appear as unattractive and as masculine as possible if they are to succeed" might indeed be sound for those who want to report on traditionally masculine news topics.

Finally, a comment on the state of knowledge about gender in media scholarship. Cultural studies approaches should be credited for its long commitment and prolific yielding of insights into matters related to media and gender. Quantitative approaches to gender research represent a comparatively small and scattered contribution to this field of media research. The findings reported here perhaps serve as a reminder that quantitative investigations and theoretical pluralism are needed to advance a full-bodied account of the receptionend of gendered message content. 
References cited

Barry, A. M. (2005). Perception theory. In Ken Smith, Sandra Moriarty, Gretchen Barbatsis, and Keith Kenney (Eds.), Handbook of visual communication (pp. 45-62). Mahwah, NJ: Lawrence Erlbaum Associates.

Basil, M. D. (1992, May). Attention to and memory for audio and video information in television scenes. Paper presented at the annual meeting of the International Communication Association. Miami, FL.

Beasley, M., \& Creedon, P. J. (1989). Newspapers: is there a new majority defining the news? In Creedon, P. (Ed.) Women in mass communication: Challenging gender values, pp. 180-194. Thousand Oaks, CA: Sage

Blass, T., Alperstein, L., \& Block, S. H. (1974). Effects of communicator's race and beauty and of receiver's objectivity-Subjectivity on attitude change. Proceedings of the Division of Personality and Social Psychology, pp. 132-134. Washington, D.C.: American Psychological Association.

Buss, D. M. (1988). The evolution of human intrasexual competition: Tactics of mate attraction. Journal of Personality and Social Psychology, 54(4). 616628.

Buss, D. M. (1989). Sex differences in human mate preferences: Evolutionary hypotheses tested in 37 cultures. Behavioral and Brain Sciences, 12, 1-49.

Buss, D. M. \& Barnes, M. (1986). Preferences in human mate selection. Journal of Personality and Social Psychology, 50, 559-570.

Cann, D. (2001). Journalist and source gender in Australian television news. Journal of Broadcasting \& Electronic Media, 45, 162-185.

Carter, C., Branston, G. \& Allan, S. (1998). News, gender, and power. NY, NY: Routledge. 
Cash, T. F. (1985). The impact of grooming style on the evaluation of women in management. In M. R. Solomon (Ed.) The psychology of fashion, pp. 343355. Lexington, MA: Lexington Books.

Cashdan, W. (1996). Women's mating strategies. Evolutionary Anthropology, 5, $134-143$

Chestnut, R. W., LaChance, C. C., \& Lubitz, A. (1971). The decorative female model: Sexual stimuli and the recognition of advertisements. Journal of Advertising, 6, 11-14.

Creedon, P. \& Cramer, J. (2007). Our conclusion: Gender values remain, inequity resurges, and globalization brings new challenges. In Creedon, P. \& Cramer, J. (Eds.), Women in mass communication, pp. 275-283. Thousand Oaks, CA: Sage.

D'Ambrosio, D. (July 21, 2009). Beyond the Headlines: Fox 61 News reporter Shelly Sindland's allegations of ageism and sexism have garnered a lot of attention, but what about her charge that the news is for sale at her station? The Hartford Advocate. Retrieved on 9/28/09 from http://www.hartfordadvocate.com/article.cfm?aid=13940.

Desmond, R. \& Danilewicz, A. (forthcoming). Women are on, but not in, the news: Gender roles in local television news. Sex Roles.

Dion, K. K., Berscheid, E. \& Walster, E. (1972). What is beautiful is good. Journal of Personality and Social Psychology, 24, 285-290.

Drew, D., \& Grimes, T. (1987). Audio-visual redundancy and TV news recall. Communication Research, 14(4), 452-461.

Duits, L. van Zoonen, L. (2007). Who's afraid of female agency? A rejoinder to Gill. European Journal of Women's Studies, 14(2), p. 161 -170. 
Dural, S., Çetinkaya, H. \& Gülbetekin, E. (2008). The role of waist-to-hip ration in evaluation of female physical attractiveness: Eye-tracker data. Turkish Journal of Psychology, 23(61), 89-91.

Eagly, A. H., Ashmore, R. D., Makhijani, M. G., \& Longo, L. C. (1991). What is beautiful is good, but...: A meta-analytica review of researcg on the physical attractiveness stereotype. Psychological Bulletin, 110(1), 109128.

Ellerbee, L. (1986). And so it goes: Adventures in television. New York, NY: G. P. Putnam's Sons.

Elliot, A. J. \& Niesta, D. (2008). Romantic red: Red enhances men's attraction to women. Journal of Personality and Social Psychology, 95(5), 1150-1164.

Engstrom, E. \& Ferri, A. J. (2001). Looking through a gendered lens: Local U. S. television news anchors' perceived career barriers. Journal of Broadcasting \& Electronic Media, 44, 614-634.

Feingold, A. (1990). Gender differences in effects of physical attractiveness on romantic attraction: A comparison across five research paradigms. Journal of Personality and Social Psychology, 59, 981-993.

Ferri, A. J. (1988). Perceived career barriers of men and women television news anchors. Journalism \& Mass Communication Quarterly, 65, 661-667.

Ferri, A. J. \& Keller, J. (1986). Perceived career barriers for female television news anchors. Journalism Quarterly, 63, 463-467.

Fink, B. \& Penton-Voak, I. (2002). Evolutioanry psychology of facial attractiveness. Current Directions in Psychological Science, 11, 154-158.

Flint, J. (6 January 2005). An old story in TV news: Former Weather Channel reporter charges age bias. The Wall Street Journal, A11. 
Grabe, M. E. \& Bucy, E. P. (2009). Image Bite Politics: News and the Visual Framing of Elections. New York, NY: Oxford University Press.

Grabe, M. E. \& Kamhawi, R. (2006). Hard wired for negative news? Gender differences in processing broadcast news. Communication Research, 33(5), 346-369.

Graber, D. A. (1990). Seeing is remembering: How visuals contribute to learning from television news. Journal of Communication, 40, 134-155.

Grammer, K., Fink, B., Moller, A. P., \& Thornhill, R. (2003). Darwinian aesthetics: Sexual selection and the biology of beauty. Biological Review, $78,385-407$.

Grimes, T. (1991). Mild auditory-visual dissonance in television news may exceed viewer attentional capacity. Human Communication Research, 18(2), 268-298.

Gründl, M., Eisenmann-Klein, M., \& Prantl, L. (2009). Quantifying female body attractiveness by a statistical analysis of body measurements. Plastic and Reconstructive Surgery, 123(3), 1064-1071.

Harp, D. A., Harp, S. S., \& Stretch, S. M. (1985). Apparel impact on viewer responses to television news anchorwomen. Southwestern Mass Communication Journal, 1(1), 49-60.

Haselton, M. G., Mortezaie, M., Pillsworth, E. G., Bleske-Rechek, A., \& Frederick, D. A. (2007). Ovulatory shifts in human female ornamentation: Near ovulation, women dress to impress. Hormones and Behavior, 51, 4045. 
Heilman, M. E. \& Saruwatari, L. R. (1979). When beauty is beastly: The effects of appearance and sex on evaluations of job applicants for managerial and nonmanagerial jobs. Organizational Behavior and Human Performance, 23(3), 360-372.

Heilman, M. E. \& Stopeck, M. H. (1985). Attractiveness and corporate success: Different causal attributions for males and females. Journal of Applied Psychology, 70(2), 1985. 379-388.

Holland, P. (1987). When a woman reads the news in Helen Baehr and Gillian Dyer (eds.) Boxed-in: Women and television, pp. 133-150. London: Pandora.

Horai, J., Naccari, N., Fatoullah, E. (1974). The effects of esprtise and physical attractiveness upon opinion agreement and liking. Sociometry, 37, 601606.

Hosoda, M., Stone-Romero, E. F., \& Coats, G. (2003). The effects of physical attractiveness on job-related outcome: A meta-analysis of experimental studies. Personnel Psychology, 56, 431-462.

Jackson, L. A. (1992). Physical appearance and gender: Sociobiological and sociocultural perspectives. Albany: State University of New York Press.

Jackson, L. A., Sullivan, L. A., \& Rostker, R. (1988). Gender, gender role, and body image. Sex Roles, 19, 429-443.

Johnston, V. S. (1999). Why we feel: The science of human emotions. Cambridge, MA: Perseus Publishing.

Kardum, I., Hudek-Knezevic, J. \& Gracanin, A. (2006). Sociosexuality and mate retention in romantic couples. Psychological Topics, 15(2), 277-296. 
Kim, K. H. (2006). Obstacles to the success of female journalists in Korea. Media, Culture, and Society, 28, 123-141.

Lang, A. (1995). Defining audio/video redundancy from a limited-capacity information processing perspective. Communication Research, 22(1), 86115.

Lang, A. (2006a). Motivated cognition LC4MP: The influence of appetitive and aversive activation on the processing of video games. In P. Messarsis and L. Humphries (Eds.), Digital media: Transformation in human communication (pp. 237-256). New York, NY: Peter Lang Publishing. Lang, A. (2009). The limited capacity model of motivated mediated message processing. In Robin L. Nabi and Mary Beth Oliver (Eds.), The SAGE handbook of media processes and effects (pp. 193-204). London, UK: SAGE Publications Ltd.

Lang, A., Newhagen, J., \& Reeves, B. (1996). Negative video as structure: Emotion, attention, capacity, and memory. Journal of Broadcasting \& Electronic Media, 404, 460-477.

Lang, A., Potter, R., Bolls, P. (1999). Something for Nothing: Is Visual Encoding Automatic?. Media Psychology, 1(2), 145-164.

Langlois, J. H., Kalakanis, L., Rubenstein, A. J., Larson, A., Hallam, M. \& Smoot, M. (2000). Maxims of myths of beauty? A meta-analytic and theoretical review. Psychological Bulletin, 126(3), 390-423.

Lillie, E., Mader, J., \& Ray, S. (2009). Beauty and the news. New Social Scientist Review. Retrieved on 9/28/09 from

http://cara.georgetown.edu/staff/webpages/New\%20Social\%20Scientist\%20Revie w\%20Sp09.pdf 
Lumby, C. (1994). Feminism and the media: The biggest fantasy of all. Media Information Australia, 72, 49-54.

Luxen, M. F. \& van der Vijver, F. J. R. (2006). Facial attractiveness, sexual selection, and personnel selection: When evolved preferences matter. Journal of Organizational Behavior, 27, 241-255.

Newhagen, J. E. \& Reeves, B. (1992). The evening's bad news: Effects of compelling negative television news images on memory. Journal of Communication, 42(2), 25-41.

Nicholson, J. (2007). Women in newspaper journalism (Since the 1990s). In Creedon, P. \& Cramer, J. (Eds.), Women in mass communication, pp. 3547. Thousand Oaks, CA: Sage.

Nitz, M., Reichert, T., Aune, A. S., Velde, A. V. (2007). All the news that's fit to see? The sexualization of television news journalists as a promotional strategy. Journal of Promotion Management, 13(1/2), 13-33.

Patzer, G. L. (1983). Source credibility as a function of communicator physical attractiveness. Journal of Business Research, 11, 229-241.

Rakow, L. F. \& Kranich, K. (1991). Woman as sign in television news. Journal of Communication, 41(1), 8-23.

Regas,J. C. \& Kozlowski, K. (1998). Red my lips: A cultural history of lipstick. San Francisco: Chronicle Books.

Singh, D. (1993) Adaptive significance of female physical attractiveness: Role of waist-to-hip ratio. Journal of Personality and Social Psychology, 65, 292307.

Singh, D. (2004). Mating strategies of yong women: Role of physical attractiveness, The Journal of Sex Research, 41, 43-54. 
Singh, D. (2006). Universal allure of the hourglass figure: An evolutionalry theory of female physical attractiveness. Clinics in Plastic Surgery, 33, 359-370.

Singh, D. \& Randall, P. K. (2007). Beauty is in the eye of the plastic surgeon: Waist-hip ratio (WHR) and women's attractiveness. Personality and Indidvidual Differences, 43, 329-240.

Sitt, P. (2003, October 31). Bias suit is filed against KIRO-TV, ex-anchorwoman says her age, race figured in job lose. The Seattle Times, B1.

Smee, T. W. (2004, August). Does a news anchor's gender influence audience evaluations of the anchor? Paper was presented at the Association for Education in Journalism and Mass Communication in Toronto, Canada.

Smith, S. B. (1983, August 6). TV newswoman's suit stirs a debate on values in hiring. The New York Times, p. A1.

Smith, S.B. (1983, August 6). TV newswoman's suit stirs a debate on values in hiring. The New York Times, A1.

Snyder, M. \& Rothbart, M. (1971). Communication attractiveness and opinion change. Canadian Journal of the Behavioral Sciences, 3, 377-387,

Soderlund, W. C., Surlin, S. H., \& Romanow, W. I. (1989). Gender in Canadian local television news: Anchors and reporters. Journal of Broadcasting \& Electronic Media, 33, 187-196.

Steadman, M. (1969). How sexy illustrations affect brand recall. Journal of Advertising Research, 9, 15-19.

Steiner, L. (2007). Sexed and gendered bodies in journalism textbooks. In Creedon, P. \& Cramer, J. (Eds.), Women in mass communication, pp. 923. Thousand Oaks, CA: Sage. 
Symons, D. (1979). The evolution of human sexiuality. New York, NY: Oxford University press.

The Boston Globe (1999, March 21). Judge cuts award to anchorwoman. The Boston Globe, F4.

The Buffalo News (2002, August 2). Kaplan making news with suit, but questions are sure to follow. The Buffalo News, D3.

Thiel Stern, S. (2007). Increased legitimacy, fewer women? Analyzing editorial leadership and gender in online journalism. In Creedon, P. \& Cramer, J. (Eds.), Women in mass communication, pp. 133-147. Thousand Oaks, CA: Sage.

Thornton, M. (1983, August 9). Newscaster wins \$500,000. The Washington Post, A1.

Thorson, E., \& Lang, A. (1992). The Effects of Television Videographics and Lecture Familiarity on Adult Cardiac Orienting Responses and Memory. Communication Research, 193, 346-369.

Udry, J. R. \& Eckland, B. K. (1984). Benefits of being attractive: Differential payoffs for men and women. Psychological Reports, 54, 47-56.

van Hoof, M. H., Voorhorst, F. J., Kaptein, M. B., Hirasing, R. A., Koppenaal, C. \& Schoemaker, J. (2000). Insulin, androgen, and gonodatropin concentration, body mass index, and waist to hip ratio in the first yeats after menarche in girls with regular menstrual cycle, irregular menstrual cycles, or oligomenorrhea. Journal of Clinical Endocrinology and Metabolism, 85, 1394-1400. 
Weaver, D., Beam, R., Brownlee, B., Voakes, P., \& Wilhoit, C. (2007). The American journalist in the $21^{\text {st }}$ century. US news people at the dawn of a new millennium. Mahwah, NJ: Lawrence Erlbaum.

Weibel, D. Wissmath, B. \& Groner, R. (2008). How gender and age affect newscasters' credibility_An investigation in Switzerland. Journal of Broadcasting \& Electronic Media, 52(3), 466-484.

Womack, S. (2005, February 10). A female TV news presenter is single man's ideal date. Retrieved on 9/28/09 from http://www.telegraph.co.uk/news/uknews/1483180/A-female-TV-newspresenter-is-single-mans-ideal-date.html 
Table 1.

Paired samples t-test results for manipulation check measures.

\begin{tabular}{|c|c|c|c|c|}
\hline Dependent variable & $\begin{array}{c}M \\
\text { Sexualized }\end{array}$ & $\begin{array}{c}M \\
\text { Unsexualized }\end{array}$ & $t$ & $p$ \\
\hline How feminine is the anchor? & $\begin{array}{c}6.91 \\
(1.48)\end{array}$ & $\begin{array}{c}4.40 \\
(1.62)\end{array}$ & 10.93 & .001 \\
\hline How attractive is the anchor? & $\begin{array}{c}5.34 \\
(1.79)\end{array}$ & $\begin{array}{l}4.10 \\
1.75)\end{array}$ & 6.20 & .001 \\
\hline $\begin{array}{l}\text { If you were a heterosexual male, } \\
\text { how interested would you be in } \\
\text { asking her out on a date? }\end{array}$ & $\begin{array}{l}4.28 \\
(2.11)\end{array}$ & $\begin{array}{c}3.00 \\
(1.81)\end{array}$ & 5.62 & .001 \\
\hline $\begin{array}{l}\text { How much do you think someone } \\
\text { on a date with her would be } \\
\text { willing to spend on the evening? }\end{array}$ & $\begin{array}{c}5.43 \\
(1.64)\end{array}$ & $\begin{array}{c}4.15 \\
(1.87)\end{array}$ & 6.53 & .001 \\
\hline $\begin{array}{l}\text { How often do you think she gets } \\
\text { asked out on a date? }\end{array}$ & $\begin{array}{c}5.47 \\
(1.77)\end{array}$ & $\begin{array}{c}3.83 \\
(1.79)\end{array}$ & 7.89 & .001 \\
\hline $\begin{array}{l}\text { How sexy is the anchor by } \\
\text { general standards? }\end{array}$ & $\begin{array}{c}4.63 \\
(1.84)\end{array}$ & $\begin{array}{c}3.00 \\
(1.65)\end{array}$ & 7.50 & .001 \\
\hline
\end{tabular}

Notes. Standard deviations are in parentheses below means. For all analyses:

Degrees of freedom $=81$ and $N=82$. 
Table 2.

Notable F-test results for analysis of co-variance on dependent measures

\begin{tabular}{|c|c|c|c|}
\hline & $F$ & $p$ & $\eta^{2}$ \\
\hline \multicolumn{4}{|l|}{ Professionalism index: } \\
\hline Main Effect, Gender & 6.18 & .013 & .02 \\
\hline Version $\times$ Gender & 3.80 & .050 & .01 \\
\hline \multicolumn{4}{|l|}{ Professionalism open-ended comments: } \\
\hline Main Effect, version (section A) comments & 5.64 & .018 & .02 \\
\hline Main Effect, version (section A) neutral & 7.36 & .007 & .03 \\
\hline Main Effect, version (section B) positive & 4.66 & .033 & .01 \\
\hline Main effect, gender (section A) positive & 3.15 & .077 & .01 \\
\hline Main effect, gender (section A) negative & 7.84 & .006 & .03 \\
\hline Main effect, gender (section $C$ ) negative & 3.15 & .079 & .03 \\
\hline Version $\times$ Gender $($ section $C$ ) negative & 2.80 & .038 & .04 \\
\hline \multicolumn{4}{|l|}{ Fitness for beat: } \\
\hline Main Effect, version: war & 12.76 & .001 & .03 \\
\hline Main Effect, version: politics & 8.53 & .004 & .02 \\
\hline Version $\times$ Gender: war & 7.00 & .008 & .02 \\
\hline Version $\times$ Gender: politics & 8.50 & .004 & .02 \\
\hline \multicolumn{4}{|l|}{ Encoding: } \\
\hline Main Effect, version: visual & 6.54 & .010 & .02 \\
\hline Main effect, gender: visual & 33.90 & .001 & .09 \\
\hline Main effect, gender: verbal & 9.61 & .002 & .02 \\
\hline Version $\times$ Gender: visual & 8.07 & .005 & .02 \\
\hline Version $\times$ Gender: verbal & 17.07 & .001 & .04 \\
\hline
\end{tabular}


Figure I.

Interaction effect for gender of subject and sexualization of anchor on the professionalism index.

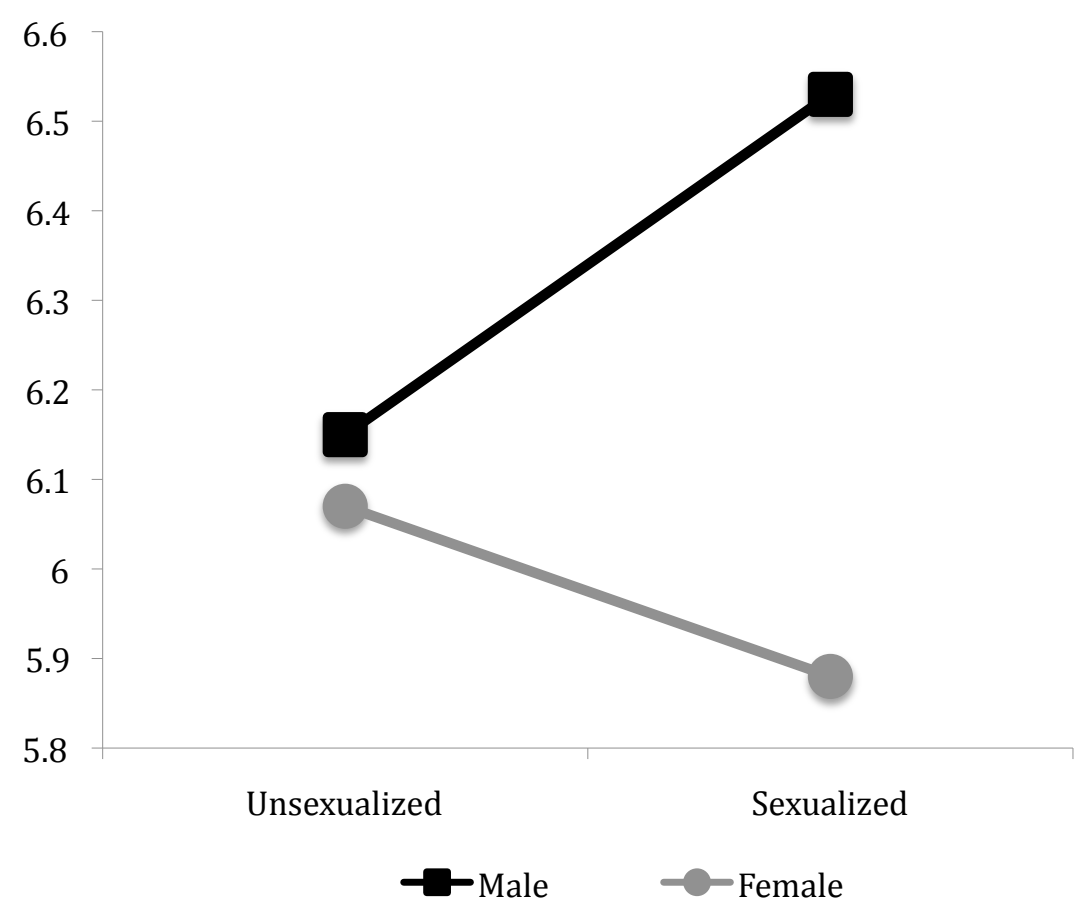


Figure 2.

Interaction effect for gender of subject and sexualization of anchor on prompted negative open-ended responses.

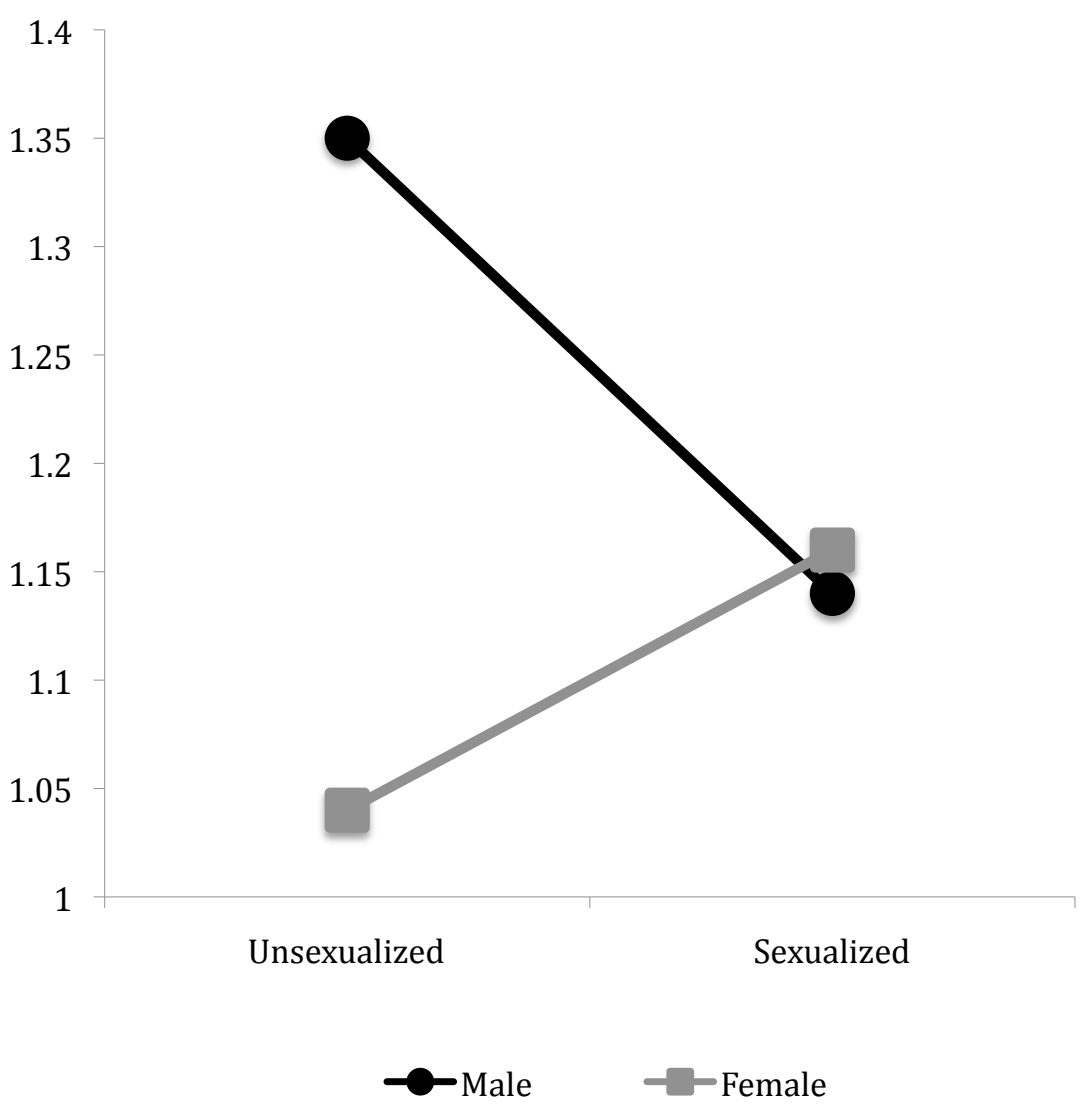


Figure 3.

Interaction effect for gender of subject and sexualization of anchor on the fitness for war corresponding.

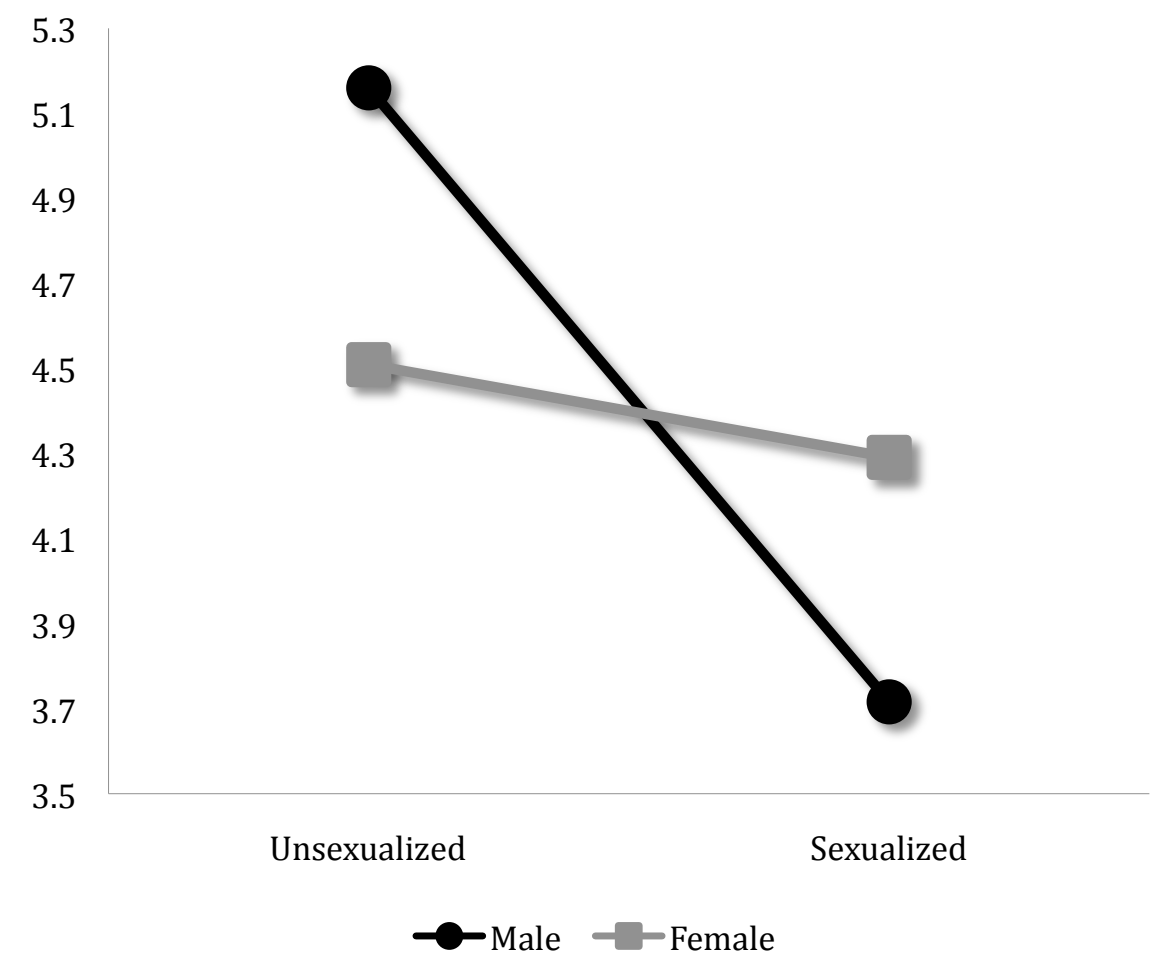


Figure 4.

Interaction effect for gender of subject and sexualization of anchor on the fitness for political reporting.

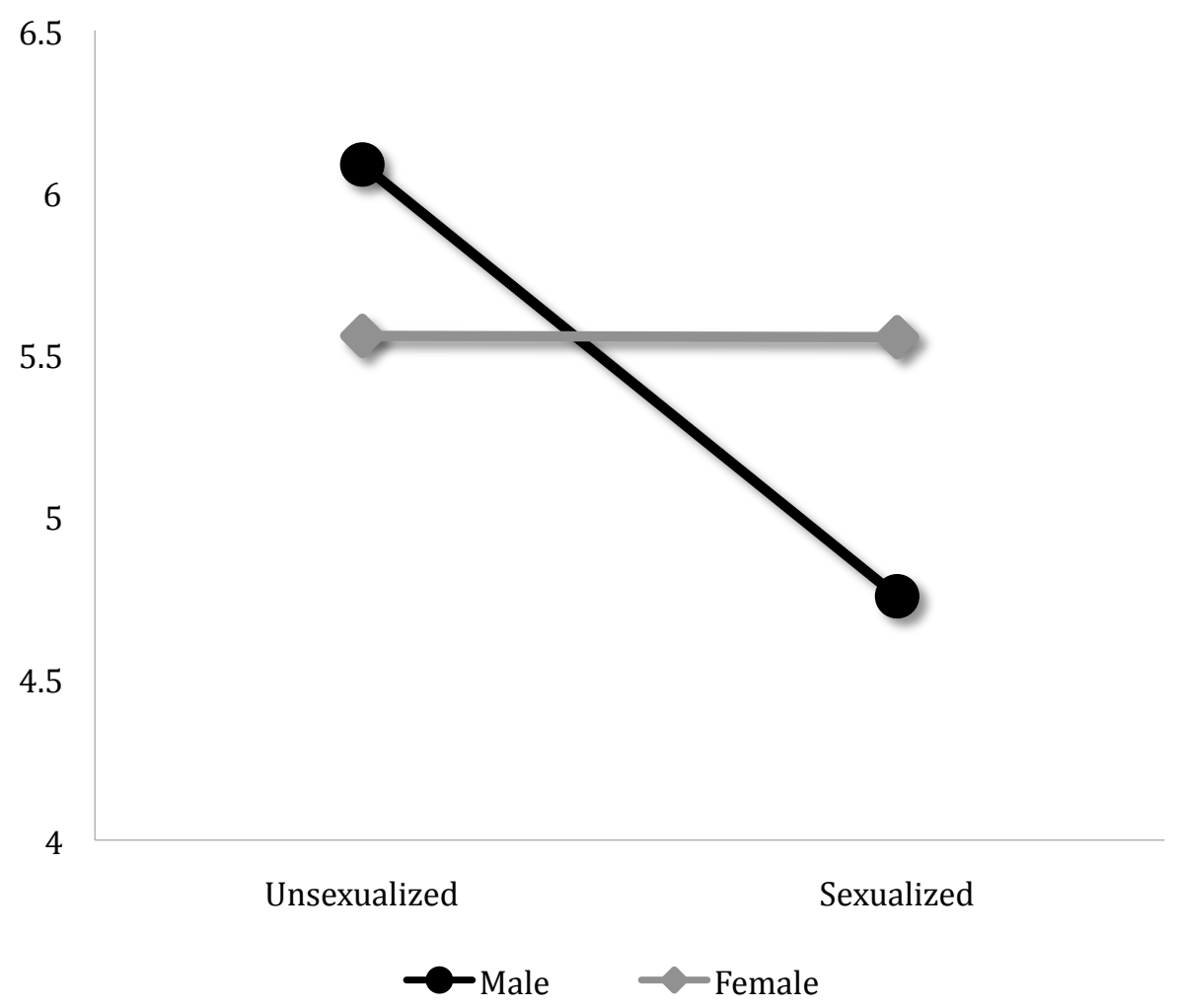


Figure 5.

Interaction effect for gender of subject and sexualization of anchor on the encoding of verbal content.

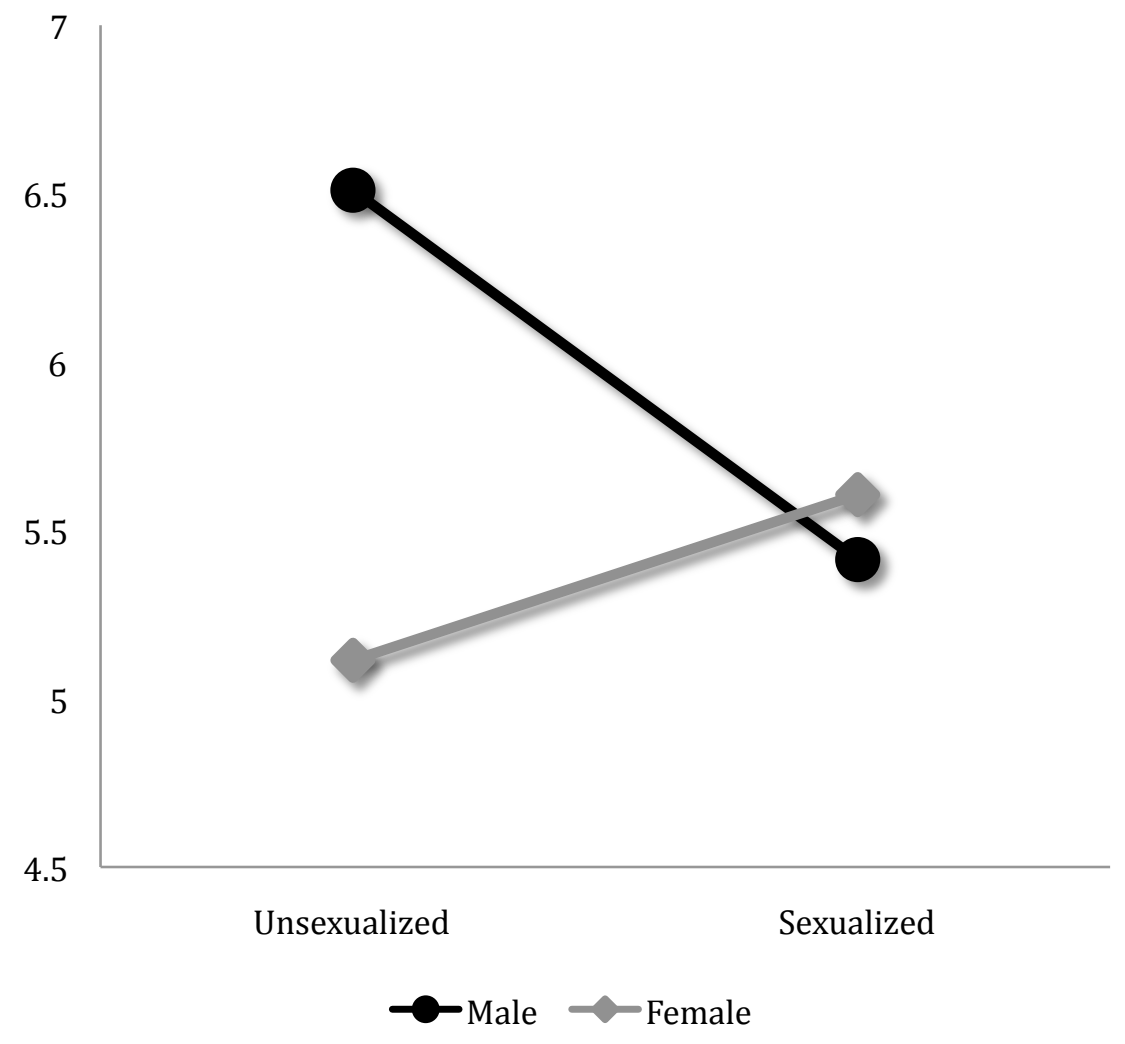


Figure 6.

Interaction effect for gender of subject and sexualization of anchor on the encoding of visual content.

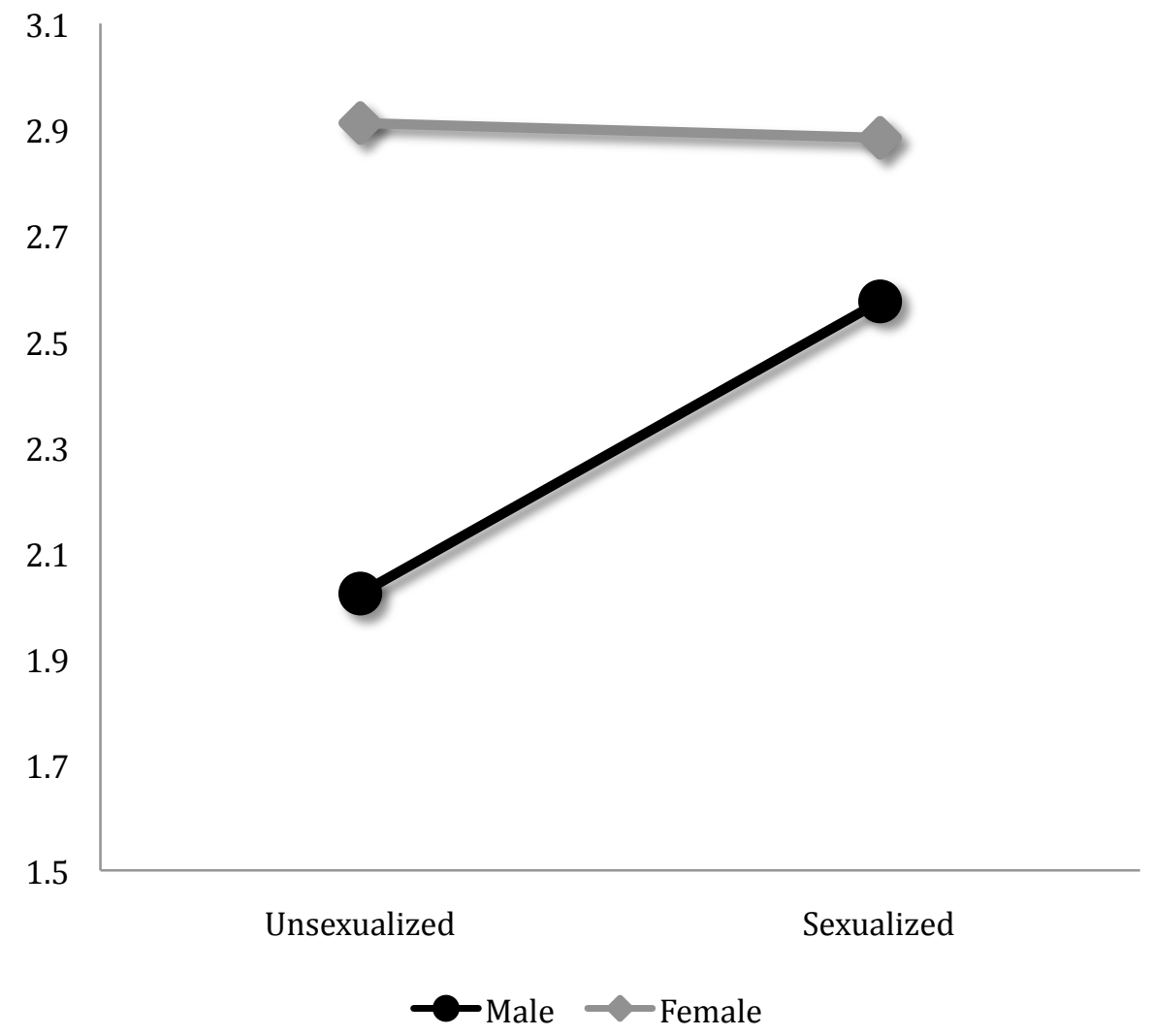


Notes.

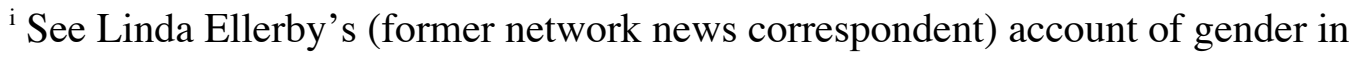
the newsroom.

ii The charges were dismissed by a U.S. District Court Judge in 2005 (The Buffalo News, 2002).

iii In 2006, The Weather Channel settled for an undisclosed amount.

${ }^{\text {iv }}$ Vertical lines, straight silhouettes, strong angular lines, large scale details, heavy textures, dark colors.

${ }^{v}$ No make-up or jewelry, uncombed hair, and wrinkled shirt. 